\title{
The impact of pediatric blood and marrow transplant on parents: introduction of the parent impact scale
}

Katherine E Heinze ${ }^{1 *}$, Angie Mae Rodday ${ }^{2}$, Marie T Nolan ${ }^{1}$, Kristin Bingen ${ }^{3}$, Mary Jo Kupst ${ }^{3}$, Sunita K Patel ${ }^{4}$, Karen Syrjala ${ }^{5}$, Lynnette Harris ${ }^{6}$, Christopher Recklitis ${ }^{7}$, Lisa Schwartz ${ }^{8}$, Stella Davies ${ }^{9}$, Eva C Guinan ${ }^{7}$, Robert Noll ${ }^{10}$, Grace Chang ${ }^{11}$ and Susan K Parsons ${ }^{2}$

\begin{abstract}
Background: Parents often experience stress-related complications when their child requires blood and marrow transplant (BMT). Previous studies have described the emotional toll BMT places on parents during the acute phase of care and within the context of clinical complications. In this paper we introduce the Parent Impact Scale (PARimpact), designed to capture physical and emotional challenges of the child's health on the parent. The primary aim of this paper is to examine psychometric properties of PARimpact, and the secondary aim is to explore factors associated with PARimpact scores for further hypothesis generation.

Methods: This analysis used a merged dataset of two longitudinal studies. Accompanying parents $(n=363)$ of children undergoing BMT were surveyed up to six times from pre-BMT baseline to one year after their child's BMT. For this analysis, pre-BMT baseline responses to PARimpact were used to examine the factor structure with Principal Component Analysis (PCA) and Exploratory Factor Analysis (EFA). Construct validity was assessed, and multivariable regression was used to examine relationships between PARimpact and BMT clinical variables.

Results: PCA and EFA revealed a one-factor solution with acceptable item loading; Cronbach's a was 0.83 at baseline. Hypothesized differences in known groups were detected for BMT complications with significantly higher PARimpact scores for those with vs. without each complication. In the adjusted multivariable regression models, acute graft versus host disease $(b=5.3 ; p=0.03)$, end organ toxicity $(b=5.9 ; p<0.01)$, and systemic infection $(b=9.1 ; p<0.01)$ were associated with significantly higher mean PARimpact scores in the first 3 months following transplant. After the first 3 months to 1 year post BMT, systemic infection was associated with increased mean PARimpact scores $(b=19.2$; $p<0.01)$.

Conclusions: Initial results suggest that the PARimpact is valid and reliable. Our finding that clinical complications increase the impact of BMT on the caretaking parent indicates the need for BMT healthcare professionals to identify these events and help parents navigate the BMT course. Clinical application of the PARimpact scale should be considered to identify high-risk families and provide targeted interventions to augment care.
\end{abstract}

Keywords: Blood and marrow transplantation, Caregiving, Stress, Parent impact

\footnotetext{
* Correspondence: kgriff12@jhu.edu

'Johns Hopkins University School of Nursing, 525 N Wolfe Street, Baltimore, MD 21205, USA

Full list of author information is available at the end of the article
} 


\section{Introduction}

Blood and marrow transplant (BMT) offers children with life-threatening illness, and their families, hope of durable cure when no other curative treatment is available [1]. However, parents of children undergoing BMT often experience a great deal of stress [2], and are at risk for short and long-term psychosocial sequelae, such as depression, anxiety, post-traumatic stress symptoms, and decreased quality of life (QOL) [3-6]. While some prospective studies have shown that parental well-being is most affected during the acute phase of the BMT and then improves with time, there is evidence that the pattern is more nuanced, and is related to other variables, such as previous emotional history and the clinical complications of the BMT [5,7-10]. Furthermore, retrospective studies show some bereaved and non-bereaved parents continue to experience distress for years after the BMT [11-13].

Enhancing our understanding of the parent, family, and BMT characteristics that are associated with increased parental impact may help clinicians identify parents most at risk, and lead to the development of interventions to support parents through the BMT trajectory. In one study of 49 parents/guardians of BMT recipients, $81 \%$ of parents/guardians reported they felt proceeding to BMT was their only choice, given its life-saving potential [14]. Because of the high stakes and demands of the treatment, support for these potentially vulnerable parent caregivers is paramount.

Previous research has documented that parental distress [9] and diminished parent emotional functioning are associated with BMT [7]. What has not been described is the direct effect of the child's emotional and physical condition on parents, and their ability to manage other obligations, such as work. In this paper we introduce the Parent Impact Scale (PARimpact), a scale within the Child Health Ratings Inventories (CHRIs), [15] designed to capture the physical and emotional impact of the child's health condition on the parent. In this context, 'impact' is considered in the negative sense, conferring challenges to the parent. The primary aim of this analysis is to examine the psychometric properties of the PARimpact as a "stand-alone" scale of the impact of children's BMTs on parents, and parents' ability to meet their own needs. A secondary aim is to explore factors associated with PARimpact scores for further hypothesis generation.

\section{Methods}

Data for this analysis were drawn from a merged dataset of two completed dyadic longitudinal health-related quality of life (HRQL) studies comprised of children undergoing $\mathrm{BMT}$ and their accompanying parent
(Journeys to Recovery (JTR) and HSCT-CHESS ${ }^{\mathrm{Tm}}$, described elsewhere [16-18]). Data were collected at eight pediatric BMT centers across the United States from 2003-2011 at clinically relevant time points: pre-BMT baseline, 45 days (represents the end of the inpatient hospitalization period), 3 months (end of the acute BMT period), 6 months, 9 months (HSCT-CHESS ${ }^{\text {mix }}$ only), and one year after transplant (designed to capture the late complications and recovery period). Both source studies, including data from the PARimpact Scale described in this paper, were approved by the Tufts Medical Center Institutional Review Board (IRB) and the IRB at each research center. IRB approval was also obtained from Tufts Medical Center and Johns Hopkins University to combine the data for this analysis in accordance with the Helsinki Declaration.

Survey data in this study were drawn from the CHRIsGeneral, a generic HRQL measure with child, adolescent, and parent versions. The CHRIs contains scales to measure HRQL and related constructs: HRQL scales measure emotional, physical, and role functioning, which together represent the multi-dimensional construct of HRQL [19], while the PARimpact and global QOL scales measure related constructs. The separate global QOL scale consists of nine items in which the respondent rates their overall quality of life in the areas of physical health, emotional health, and social health [15]. The CHRIs scales have been extensively validated within the pediatric BMT population $[6,15]$.

\section{Study sample}

Accompanying parents of pediatric patients aged 2 months to 18 years who were scheduled to undergo BMT at study sites were consecutively recruited. Dyadic participation of the parent and child was required. Inclusion criteria for parents were: ability to speak/understand English, at least 18 years old, parent or legal guardian of the BMT patient, and ability to provide consent to participate both for him or herself as well as for the BMT patient. While only parent data were included in this analysis, age-eligible child participants also provided assent (participants $<18$ years) or consent (participants $\geq 18$ years) for his or her participation. Overall, $62 \%$ of eligible dyads consented to participate. Common reasons for non-participation included child refusal (27\%), parent refusal (44\%), and medical reasons (3\%). Participants did not differ from non-participants based on child age, gender, or race/ethnicity.

A total of 423 parents were enrolled in the JTR and HSCT-CHESS $^{\text {tw }}$ studies; 60 parents of children less than 5 years old were excluded from this analysis because in the JTR study parents of children in this age group did not complete the CHRIs, which left 363 parents in this analysis. 


\section{Measures}

\section{Parent Impact Scale}

The PARimpact was developed as a separate scale within the parent-proxy version of the CHRIs-General to measure the response of the parent to the child's physical and emotional health needs. The scale consists of four items with five response options on a frequency-based Likerttype scale ranging from "none of the time" to "all of the time" (see Table 1 for PARimpact questions). The scale scores range from 0-100 with higher scores indicating greater parent impact. Starting 45 days after transplant ("day 45" the second data collection point), three additional open-response items were administered alongside the PARimpact scale items to ascertain the actions that parents took in the previous seven days as a result of their child's BMT. These included the number of missed work days in the past week due to the child's health, missed work days due to the parent's health, and the number of days someone came to help the family in the past week. While these items were not designed to be part of the scored PARimpact Scale, they are a related set of items that complement the PARimpact scale. Among these three items we focused on missed workdays due to the child's health for this analysis.

\section{Parent Emotional Functioning}

The Parent Emotional Functioning scale within the parentproxy CHRIs General consists of seven questions measuring parent mood, anxiety, and distress [5,6,20]. The response options for each item utilize a five-point Likert-type scale. Scale scores range from 0-100 with higher scores denoting better emotional functioning. In the JTR study, the Parent Emotional Functioning scale demonstrated strong prediction of DSM-IV Axis 1 disorders, based on area under the receiver operating characteristic curve [21] for predicting a threshold or sub-threshold disorder from related modules of the Structured Clinical Interview for DSM-IV Axis 1 disorders (c-statistic $=0.75)$ [20].

\section{Parent Global QOL}

The parent version of the Global QOL scale of the CHRIs consists of nine questions designed to capture the multidimensionality of QOL as physical, mental, and social well-being. Responses are measured with a Likerttype scale with five response options ranging from "poor" to "excellent." The scale is scored from 0-100, with higher scores indicating higher QOL [16].

\section{Parent General Health}

The General Health item in the CHRIs is a single summary item of parents' general health appraisal. Parents were asked, "Overall, how would you rate your health"; response options include a five-point Likert-type scale, which is scored on a $0-100$ scale with higher scores indicating better health. This item has been used extensively in clinical practice and research [22] and has been found to be associated with multi-item scales of general health and other markers of disease and clinical outcomes [23].

\section{Clinical variables}

Clinical data were collected at all assessment time points by trained study staff, using standardized data collection instruments. All clinical data were reviewed by the study PI (SKP) for completeness and consistency. Pre-BMT baseline information included time since diagnosis (months), disease category (malignant or non-malignant), and transplant type (related allogeneic, unrelated allogeneic, or autologous). In follow up, specific clinical outcomes variables used in this analysis included early and late BMT complications, defined below.

\section{Early BMT complications}

We assessed early BMT complications with standardized grading scales that assess both presence or absence and severity of the following: acute graft versus host disease (aGVHD) [24]; end organ toxicity, based on the Bearman Toxicity Scale; [25] and systemic infection, based on the National Cancer Institute's Common Toxicity Criteria for AE, v. 3.0 [26]. Each of the early BMT complications was dichotomized as follows: grade 2 or higher aGVHD; Bearman Toxicity Score maximum ratings of "intermediate" or "poor" within the first 3 months posttransplant; and grade 3 or higher infection, indicating systemic and/or life-threatening infection.

Table 1 PARimpact items and scores

\begin{tabular}{|c|c|c|c|c|c|}
\hline \multicolumn{6}{|l|}{ Pre-BMT baseline scores (Cronbach's $a=0.83$ ) } \\
\hline & $\mathrm{n}$ & Mean & Std. Dev. & $\%$ Floor & $\%$ Ceiling \\
\hline Summary score* & 363 & 51.41 & 24.65 & 2 & 4 \\
\hline \multicolumn{6}{|l|}{ Item summaries } \\
\hline Child's physical health causes suffering & 363 & 60.54 & 28.32 & 6 & 19 \\
\hline Child's physical health limits time for parental needs & 363 & 50.96 & 31.02 & 15 & 12 \\
\hline Child's emotional health causes suffering & 363 & 51.24 & 31.35 & 13 & 15 \\
\hline Child's emotional health limits time for parental needs & 363 & 42.91 & 30.70 & 20 & 8 \\
\hline
\end{tabular}

*PARimpact is scored from 0-100 with higher scores indicating greater impact. 


\section{Late BMT complications}

Late BMT complications were defined as the extent of chronic graft versus host disease (cGVHD) $[27,28]$ or a systemic infection that occurred after the 3-month data observation [26]. The Bearman scale was not designed for use beyond the 3-month mark post BMT.

\section{Demographic variables}

Parents' demographic data, including age, race/ethnicity, education, marital status, household income, work status (e.g., full-time, part-time), and child's insurance were collected from parent participants at pre-BMT baseline. Parents also reported their child's race/ethnicity and sex.

\section{Statistical analysis}

Demographic and clinical characteristics were described for the combined study sample using medians (interquartile range $[\mathrm{IQR}]$ ), means (standard deviations $[\mathrm{SD}]$ ), frequencies, and percentages at pre-BMT baseline. Parents' missed work days due to the child's health were also summarized, and Spearman's correlation was used to compare this open-response item to the PARimpact scale score from day 45 to 1 year post BMT.

\section{Psychometric properties of the PARimpact scale}

Principal component analysis (PCA) was used to determine the unidimensionality of the PARimpact scale, based on data collected at pre-BMT baseline. A scree plot was used to retain components with an Eigen value greater than 1.00. Exploratory factor analysis (EFA) was completed to examine factor loadings and uniqueness. Factor loadings $>0.4$ were considered acceptable [29].

Pre-BMT baseline raw scores, means, SDs, ceiling and floor effects, and percent missing were calculated for each item within the PARimpact. Cronbach's alpha [30] was calculated to estimate the internal consistency of the scale at pre-BMT baseline. For exploratory scale development, the minimum acceptable Cronbach's alpha is 0.7 , but for established scales the minimum is 0.8 [31].

\section{Validation of the PARimpact scale}

To assess convergent validity of the PARimpact within the pediatric BMT sample, Pearson correlations were calculated between the PARimpact and other scales of the CHRIs General, including Parent Emotional Functioning, Parent Global QOL, and Parent General Health. Correlations between 0 and .30 were classified as weak, $.30-.60$ as moderate, and $>.60$ as strong [32]. We hypothesized that parent impact would be strongly correlated to parents' emotional functioning, moderately correlated with Global QOL, and weakly correlated with parents' general health. The correlations were expected to have negative valence due to the directionality of the scales (e.g. higher scores for emotional functioning suggest better functioning, while higher scores for PARimpact suggest more negative impact).

Expected variation of PARimpact scores by known groups was explored using clinically important subgroups, such as early complications, and later complications. For known group comparisons, two separate binary variables were created: (1) Early Complications, which included aGVHD $\geq$ grade 2 and/or systemic infection and/or "intermediate" or "poor" end organ toxicity; and (2) Late Complications, which included cGVHD and/or systemic infection.

\section{Regression analysis}

We built two models for regression analysis: an early model and a late model. The early model included data from pre-BMT baseline, day 45 , and 3 months. The late model included data after 3 months through 12 months post BMT. In both models, unadjusted longitudinal regressions were completed with demographic and clinical variables using residual maximum likelihood (REML). Timing of repeated assessments was calculated as the number of days since BMT. Based on a likelihood ratio test (data not shown), time was treated as continuous rather than categorical. Variables with an estimated coefficient with $\mathrm{p} \leq 0.2$ were included in the adjusted multivariable regression model. In the adjusted multivariable longitudinal regressions, variables with $\mathrm{p}>0.1$ were then removed from the model.

Auto regressive, unstructured, and compound symmetry correlation structures were compared using Akaike information criterion (AIC). To address the possibility that PARimpact scores may have been missing not at random (MNAR) over time, we stratified the final model by the extent and causes of missing data, defining strata as follows: (1) those with missing data due to a medical reason (e.g. child too sick) and (2) those with complete data or those with missing data not due to a medical reason (e.g., logistical reasons, such as transportation or work-related issues). The stratified models (called pattern mixture models, PMM) [33] assume the data are missing at random (MAR) within strata. We compared the stratified to the unstratified model using a likelihood ratio test to assess for the presence of MNAR. SAS version 9.3 was used for all statistical analyses; alpha was set at 0.05 .

\section{Results}

\section{Study sample}

Pre-BMT baseline demographic and clinical characteristics are shown in Table 2. The majority of the sample was female and Caucasian with at least some college education. Most parents reported being married or living with a partner $(80 \%)$, and reported having at least one additional child besides the BMT recipient (84\%). 
Table 2 Participant characteristics

\begin{tabular}{|c|c|c|c|c|}
\hline & \multicolumn{2}{|c|}{ Mean } & \multicolumn{2}{|c|}{ Standard Dev. } \\
\hline Child age & \multicolumn{2}{|l|}{9.6} & \multicolumn{2}{|l|}{5.1} \\
\hline Parent age & \multicolumn{2}{|l|}{38.7} & \multicolumn{2}{|l|}{7.5} \\
\hline \multirow[t]{3}{*}{ Length of illness (months) } & \multicolumn{2}{|c|}{11 (Median) } & \multicolumn{2}{|c|}{ 5, $37(\mathrm{Q} 1, \mathrm{Q} 3)$} \\
\hline & \multicolumn{2}{|c|}{ Patient } & \multicolumn{2}{|c|}{ Parent } \\
\hline & $\mathrm{n}$ & Percent & $\mathbf{n}$ & Percent \\
\hline \multicolumn{5}{|l|}{ Sex } \\
\hline Female & 169 & 47 & 301 & 83 \\
\hline Male & 194 & 53 & 62 & 17 \\
\hline \multicolumn{5}{|l|}{ Race } \\
\hline White & 291 & 81 & 277 & 77 \\
\hline Black & 24 & 7 & 21 & 6 \\
\hline Asian & 11 & 3 & 13 & 4 \\
\hline Other & 32 & 9 & 47 & 13 \\
\hline
\end{tabular}

Hispanic ethnicity

Yes

No

$\begin{array}{llll}63 & 18 & 64 & 18 \\ 297 & 83 & 297 & 82 \\ \mathbf{n} & & & \text { Percent }\end{array}$

Parent marital status

Married/living together 292

Divorced/separated/widowed 49

Never married

Other

Family income

$<\$ 20,000$

$\$ 20,000-\$ 39,999$

$\$ 40,000-\$ 79,000$

$\$ 80,000+$

Child's insurance

Private

Public

None/unknown

Parent education

$<$ High school

High school graduate

Some college

College graduate +

Number of siblings

$\begin{array}{ll}0 & 60 \\ 1 & 134 \\ 2 \text { or more } & 169 \\ \text { BMT type } & \end{array}$

Autologous

Allogeneic - related

Allogeneic - unrelated
$292 \quad 80$

$18 \quad 5$

4

$49 \quad 14$

Table 2 Participant characteristics (Continued)

\begin{tabular}{lll}
\hline BMT source & \\
Bone marrow & 200 & 55 \\
Peripheral blood & 126 & 35 \\
Umbilical cord blood & 35 & 10 \\
Other/combined & 2 & 1 \\
Death of child within 12 months & & \\
Yes & 63 & 17 \\
No & 300 & 83 \\
Disease relapse within 12 months & & 13 \\
Yes & 48 & 87 \\
No & 315 & \\
\hline
\end{tabular}

\section{PARimpact scores}

Table 1 displays PARimpact scale and item means, SDs, and floor and ceiling effects at pre-BMT baseline. For each item, the full range of possible responses from 0 100 was utilized. Variability across the scale's items was similar (SD 28.3-31.4). Responses at the floor and ceiling were $<5 \%$ for the summary score, and $\leq 20 \%$ for the individual items; there were no missing data at pre-BMT baseline.

Table 3 displays open responses to the item, "In the past week, how many days have you missed work or cut down on usual activities due to this child's health?" At 45 days after BMT, 68\% of parents reported missing work or cutting down usual activities at least one day in the previous week. At 3 months this value was $61 \%$, and at one year, it was $33 \%$. This item was moderately correlated with the PARimpact scale score, with Spearman's Rank correlation values ranging from $0.28-0.57$ across time measurements.

\section{Psychometric properties \\ $P C A$ and EFA}

PCA indicated a single component with an Eigen value of 2.6; all other Eigen values were less than 1.0. This component, "PARimpact," explained $66 \%$ of the variation in the PARimpact scale. In the EFA, factor loadings ranged from 0.60 to 0.88 , and uniqueness was $<0.20$. At pre-BMT baseline Cronbach's alpha was 0.83 , and at follow-up time points Cronbach's alpha ranged from $0.84-0.90$.

Table 3 Parent self-reported days of missed work/decreased usual activity

\begin{tabular}{lcrrr}
\hline Number of days & $\begin{array}{l}\text { Day 45 } \\
\mathbf{n}(\%)\end{array}$ & $\begin{array}{l}\text { 3 months } \\
\mathbf{n}(\%)\end{array}$ & $\begin{array}{l}\text { 6 months } \\
\mathbf{n ( \% )}\end{array}$ & \multicolumn{1}{l}{$\begin{array}{l}\text { 12 months } \\
\mathbf{n}(\%)\end{array}$} \\
\hline $\mathbf{0}$ & $93(32)$ & $111(40)$ & $140(55)$ & $156(68)$ \\
$\mathbf{1 - 3}$ & $53(18)$ & $70(25)$ & $61(24)$ & $44(20)$ \\
$\mathbf{4 - 7}$ & $146(50)$ & $100(36)$ & $55(21)$ & $29(13)$ \\
\hline
\end{tabular}




\section{Construct validity}

The PARimpact and Parent Emotional Functioning scales were strongly correlated $(-0.57$ to -0.67$)$ across time periods. The Pearson correlation for PARimpact and Global QOL ranged from -0.49 to -0.63 across time periods. General Health, which was hypothesized to be the least conceptually similar to PARimpact, was weakly or moderately correlated with PARimpact; Pearson's correlation ranged from -0.18 to -0.45 across time periods (see Table 4 for correlation coefficients at all time measurements).

Discriminant validity: results of known groups comparisons Among parents completing the 3-month assessment, 71 (37\%) BMT patients had early BMT complications. Parents of these children had a PARimpact score that was an average of 11.1 points higher than parents whose children did not experience early complications $(t=3.75$; $\mathrm{p}<0.01)$. Among parents completing the 12 -month assessment, 86 (37\%) experienced late BMT complications; parents whose children experienced late BMT complications averaged 6.8 points higher $(t=1.91 ; \mathrm{p}=0.06)$ than parents whose children did not.

\section{Regression analysis \\ Unadjusted analysis}

In the early model, none of the demographic variables met the criteria to be included in the adjusted model. Among the early complication clinical variables, aGVHD $(\mathrm{p}<0.01)$, Bearman Toxicity Score $(\mathrm{p}<0.01)$, and systemic infection $(\mathrm{p}<0.01)$ met the criteria to be included in the adjusted model.

In the late model, parent sex $(\mathrm{p}=0.05)$ was the only demographic variables to be included in the adjusted model. Among the late complication clinical variables, systemic infection $(\mathrm{p}<0.01)$ was the only variable to be included in the adjusted model.

\section{Adjusted multivariable analysis}

Based on AIC, a compound symmetry correlation structure was selected for the final model. Results of the likelihood ratio test comparing the PMM to the repeated measures model indicated the presence of MNAR (Early: $x^{2}(5)=12.7, p=0.03$; Late: $\left.x^{2} \quad(3)=16.7, p<0.01\right)$, therefore PMM estimates were used in the final models.

Table 4 Correlation coefficients for PARimpact, Global QOL, and General Health

\begin{tabular}{lrrrrr}
\hline & Pre-BMT & Day 45 & 3 months & $\mathbf{6}$ months & $\mathbf{1}$ year \\
\hline Parent Emotional & -0.57 & -0.66 & -0.60 & -0.67 & -0.66 \\
Functioning & & & & & \\
Parent Global QOL & -0.49 & -0.50 & -0.57 & -0.58 & -0.63 \\
Parent General Health & -0.18 & -0.25 & -0.37 & -0.31 & -0.45 \\
\hline
\end{tabular}

Estimated coefficients from the final models are displayed in Table 5.

In the Early model, parents of children who experienced $\geq$ grade 2 aGVHD had a mean PARimpact score that was 5 points higher than parents of children who did not $(\mathrm{p}=0.03)$. Furthermore, PARimpact scores averaged nearly 6 points higher among parents of children who had Bearman Toxicity Score of "intermediate" or "poor" ( $\mathrm{p}<0.01)$; and scores averaged 9 points higher among parents of children who experienced a systemic infection in the first 3 months following BMT $(\mathrm{p}<0.01)$.

In the Late model, parent sex did not meet the criteria to be retained in the final model $(\mathrm{p}=0.15)$. Among parents of children who experienced a systemic infection, mean PARimpact scores were 19 points higher than parents of children who did not experience a systemic infection $(\mathrm{p}<0.01)$.

\section{Discussion}

This study introduced the Parent Impact Scale, a fouritem scale of the CHRIs General parent-proxy version. A scree plot and Eigen values supported a single factor solution, and PCA indicated a single factor explained more than $60 \%$ of variation. Factor loadings and uniqueness were acceptable, and the PARimpact scale demonstrated a strong coefficient of internal consistency reliability $(\alpha=0.83)$.

The PARimpact also demonstrated hypothesized convergent and known groups validity. Specifically, the scale was strongly associated with global QOL and parent emotional functioning, but not with general health scales. In known group comparisons higher PARimpact scores were noted among parents whose children experienced early and late BMT complications $(\mathrm{p}<0.01$ and $\mathrm{p}=0.06$, respectively).

The additional open-response item of the PARimpact, assessed in follow-up time points, reveals that a high percentage of parents did miss work and/or cut down on usual activities during the year following BMT. This study is among the first to describe parents' work

Table 5 Estimated coefficients for adjusted multivariable pattern mixture models

\begin{tabular}{lrrr}
\hline & Estimate & SE & p-value \\
\hline Early (start of BMT - 3 months) & & & \\
Time & -0.07 & 0.02 & $<\mathbf{0 . 0 1}$ \\
aGVHD $\geq$ grade 2 & 5.31 & 2.48 & $\mathbf{0 . 0 3}$ \\
Bearman Toxicity & 5.91 & 1.97 & $<\mathbf{0 . 0 1}$ \\
Systemic infection & 9.09 & 2.09 & $<\mathbf{0 . 0 1}$ \\
Late (after $\mathbf{3}$ months - 1 year) & & & \\
Time & -0.02 & 0.01 & $\mathbf{0 . 0 2}$ \\
Systemic infection & 19.18 & 3.14 & $<\mathbf{0 . 0 1}$ \\
\hline
\end{tabular}


patterns and/or decrease of usual activities post transplant. By 3 months post BMT, more than 2/3 of parents took at least one day off of work and/or cut down on usual activities during the week prior to the assessment due to the child's health; by one year post BMT, nearly $1 / 3$ of parents had taken off at least one day of work - a finding that reflects the high role disruption and associated economic burden that BMT places on families. This is consistent with other studies that have found more than one year after BMT, families of children who had BMT experience a greater financial impact than families of children who underwent treatment for leukemia, but did not require BMT [13]; and that 5-10 years after BMT, families of children who underwent BMT reported more financial strain than families of children with oncologic diagnoses who did not undergo BMT [11].

PMMs, which accounted for MNAR, showed mean PARimpact scores were significantly increased with clinical BMT complications, such as moderate to severe GVHD, "intermediate" or "poor" end organ toxicity, and systemic infection, which is consistent with other findings that parent emotional functioning declined with BMT clinical complications [5]. Systemic infection was associated with significantly higher mean PARimpact scores in both early and late models (9 points and 19 points higher respectively), which may be an indication of the distress and disruption that can be associated with a life-threatening complication like systemic infection at any point in the recovery trajectory. A more complete understanding of the durability of parent vulnerability after BMT could lead to the development of interventions to decrease parent impact during and after BMT. In a retrospective study more than one year after BMT, parents indicated that education related to taking care of themselves would be helpful to parents during the BMT process [34].

\section{Strengths and limitations}

This study represents eight years of research; it is strengthened by the power of the large sample. Although the majority of the sample was White/Non-Hispanic (70\%), as is typical of studies in this clinical population, the study team was able to recruit more than $27 \%$ NonWhite or Hispanic participants. Study participants also had high educational attainment and income. The longitudinal design strengthens study findings, as does the completeness of clinical outcomes data even when patient-reported outcomes were missed. Nevertheless, as would be expected in a longitudinal study in a critically ill population, some study participants were lost to follow-up, principally due to the child's death or relapse. Rigorous study procedures were used to mitigate loss to follow-up for non-medical reasons, and PMMs were used to account for data MNAR.
Another important limitation of the current study is that all of the survey measures used to assess the convergent validity of the PARimpact were self-reported by parent participants. This can result in shared variance, which may inflate measures of construct validity. Related data on missed work were also self-reported. However, we used clinical variables to examine known group validity, which were not parent reported. Finally, it is possible that there are other variables that contribute to parent impact during a child's BMT that were not included in the PARimpact scale.

\section{Conclusion}

The promising psychometric properties of the PARimpact scale indicate that parent impact is a unidimensional construct with clinical relevance. Our findings that early and late BMT complications, such as systemic infection, significantly increase the impact of BMT on the caretaking parent indicate the need for BMT healthcare professionals to identify these events and help parents navigate the BMT course. At minimum, BMT healthcare professionals should be mindful of the additional burden on the parent that complications bring, and proactively link parents to resources to help them cope with the added impact. Further study is needed to test the validity of the PARimpact scale in other populations of caretaking parents of children with serious illnesses.

\section{Abbreviations \\ AIC: Akaike information criteria; BMT: Blood and marrow transplantation; CHRIs: Child Health Rating Inventories; EFA: Exploratory factor analysis; aGVHD: Acute graft versus host disease; CGVHD: Chronic graft versus host disease; HRQL: Health related quality of life; JTR: Journeys to Recovery; MAR: Missing at random; MNAR: Missing not at random; PARimpact: Parent Impact Scale; PCA: Principal component analysis; PMM: Pattern mixture models; QOL: Quality of Life; REML: Residual maximum likelihood.}

Competing interests

The authors declare that they have no competing interests.

\section{Authors' contributions}

$\mathrm{KH}$ completed a portion of the statistical analysis and was responsible for drafting the manuscript. AMR was responsible for the majority of the statistical analysis, providing statistical expertise, and suggesting edits to the manuscript. MN helped to guide the concepts for the analysis and suggested edits to the manuscript. KB, MJK, SKP, KS, LH, CR, LS, SD, ECG, RN, and GC provided expert opinion and suggested edits. SKP mentored the team, guided the conceptual development of the manuscript, and suggested edits. All authors read and approved the final manuscript.

\section{Acknowledgements}

$\mathrm{KH}$ acknowledges the American Cancer Society Doctoral Degree Scholarship in Cancer Nursing (DSCN-13-268-01-SCN), and the National Institute for Nursing Research (F31 NR014751-01A1) for funding this analysis. SKP acknowledges the American Cancer Society (RSG PB02-186-01-PBP) and the National Cancer Institute (R01 CA119196) for funding the Journeys to Recovery and HSCT-CHESS ${ }^{\text {TM }}$ studies, respectively.

\section{Author details}

${ }^{1}$ Johns Hopkins University School of Nursing, 525 N Wolfe Street, Baltimore, MD 21205, USA. ${ }^{2}$ Tufts Medical Center, 800 Washington Street \#345, Boston, MA 02111, USA. ${ }^{3}$ Medical College of Wisconsin, 8701 Watertown Plank Road, Milwaukee, WI 53226, USA. ${ }^{4}$ City of Hope, 1500 E. Duarte Road, Duarte, CA 
91010, USA. ${ }^{5}$ Fred Hutchinson Cancer Research Center, 1100 Fairview Avenue N, Seattle, WA 98109, USA. 'Baylor College of Medicine, One Baylor Plaza, Baylor, TX 77030, USA. 'Dana-Farber Cancer Institute, 450 Brookline Avenue, Boston, MA 02215, USA. ${ }^{8}$ University of Pennsylvania School of Medicine, 3501 Civic Center Boulevard CTRB 10311, Philadelphia, PA 19104, USA. ${ }^{9}$ Cincinnati Children's Hospital Medical Center, 3333 Burnett Avenue, Cincinnati, $\mathrm{OH}$ 45229, USA. ${ }^{10}$ Children's Hospital of Pittsburgh of PUMC, 4401 Penn Avenue, Pittsburgh, PA 15224, USA. ${ }^{11}$ Department of Psychiatry, Harvard Medical School, Boston, MA 02115, USA.

Received: 16 October 2014 Accepted: 25 March 2015

Published online: 09 April 2015

\section{References}

1. Ho SMY, Horne DJDL, Szer J. The adaptation of patients during the hospitalization period of bone marrow transplantation. J Clin Psychol Med Settings. 2002;9:167-75.

2. Rodrigue JR, MacNaughton $K$, Hoffmann RG, Graham-Pole J, Andres JM, Novak DA, et al. Transplantation in children. A longitudinal assessment of mothers' stress, coping, and perceptions of family functioning. Psychosomatics. 1997;38:478-86.

3. Packman W, Weber S, Wallace J, Bugescu N. Psychological effects of hematopoietic SCT on pediatric patients, siblings and parents: A review. Bone Marrow Transplant. 2010:45:1134-46.

4. Barrera M, Atenafu E, Doyle J, Berlin-Romalis D, Hancock K. Differences in mothers' and fathers' health-related quality of life after pediatric SCT: A longitudinal study. Bone Marrow Transplant. 2012;47:855-9.

5. Terrin N, Rodday AM, Tighiouart H, Chang G, Parsons SK. Journeys to Recovery Study. Parental emotional functioning declines with occurrence of clinical complications in pediatric hematopoietic stem cell transplant. Support Care Cancer. 2013;21:687-95.

6. Parsons SK, Shih MC, Duhamel KN, Ostroff J, Mayer DK, Austin J, et al. Maternal perspectives on children's health-related quality of life during the first year after pediatric hematopoietic stem cell transplant. J Pediatr Psychol. 2006;31(10):1100-15.

7. Rodday AM, Terrin N, Chang G, Parsons SK. Performance of the parent emotional functioning (PREMO) screener in parents of children undergoing hematopoietic stem cell transplantation. Qual Life Res. 2013;22(6):1427-33.

8. Jobe-Shields L, Alderfer MA, Barrera M, Vannatta K, Currier JM, Phipps S. Parental depression and family environment predict distress in children before stem cell transplantation. J Dev Behav Pediatr. 2009:30(2):140-6.

9. Phipps S, Dunavant M, Lensing S, Rai SN. Psychosocial predictors of distress in parents of children undergoing stem cell or bone marrow transplantation. J Pediatr Psychol. 2005;30(2):139-53.

10. Phipps S, Dunavant M, Lensing S, Rai SN. Patterns of distress in parents of children undergoing stem cell transplantation. Pediatr Blood Cancer. 2004;43(3):267-74.

11. Vrijmoet-Wiersma CM, Egeler RM, Koopman HM, Bresters D, Norberg AL, Grootenhuis MA. Parental stress and perceived vulnerability at 5 and 10 years after pediatric SCT. Bone Marrow Transplant. 2010;45(6):1102-8.

12. Drew D, Goodenough B, Maurice L, Foreman T, Willis L. Parental grieving after a child dies from cancer: Is stress from stem cell transplant a factor? Int J Palliat Nurs. 2005;11(6):266-73.

13. Clarke S. Clinical outcomes and health-related quality of life (HRQOL) following haemopoietic stem cell transplantation (HSCT) for paediatric leukaemia. Child Care Health Dev. 2011;37(4):571-80.

14. Pentz RD, Pelletier W, Alderfer MA, Stegenga K, Fairclough DL, Hinds PS Shared decision-making in pediatric allogeneic blood and marrow transplantation: What if there is no decision to make? Oncologist. 2012;17(6):881-5.

15. Parsons K, Shih C, Mayer K, Barlow E, Supran E, Levy L, et al. Preliminary psychometric evaluation of the child health ratings inventory (chris) and disease-specific impairment inventory-hematopoietic stem cell transplantation (DSII-HSCT) in parents and children. Qual Life Res. 2005;14(6):1613-25.

16. Rodday AM, Terrin N, Parsons SK. Measuring global health-related quality of life in children undergoing hematopoietic stem cell transplant: A longitudinal study. Health Qual Life Outcomes. 2013;11(1):26.

17. Kelly MJ, Pennarola BW, Rodday AM, Parsons SK. Journeys to Recovery Study, HSCT-CHESS'M Study. Health-related quality of life (HRQL) in children with sickle cell disease and thalassemia following hematopoietic stem cell transplant (HSCT). Pediatr Blood Cancer. 2012;59(4):725-31.
18. Parsons SK, Shih MC, Mayer DK, Barlow SE, Supran SE, Levy SL, et al. Caring for the caregiver: EHealth interventions for parents of pediatric hematopoietic stem cell transplant recipients. Abstract from the SIOP-psychosocial oncology (SIOP-PPO) meeting, October 21, 2011 Boston, Massachusetts, USA. Pediatr Blood Cancer. 2011;56:1159.

19. Ravens-Sieberer U, Erhart M, Wille N, Wetzel R, Nickel J, Bullinger M. Generic health-related quality-of-life assessment in children and adolescents: Methodological considerations. Pharmacoeconomics. 2006;24(12):1199-220.

20. Rodday AM, Pedowitz EJ, Mayer DK, Ratichek SJ, Given CW, Parsons SK, et al. Parental caregiving of children prior to hematopoietic stem cell transplant. Res Nurs Health. 2012;35(4):328-39.

21. Eng J. Receiver operating characteristic analysis: A primer. Acad Radiol. 2005:12(7):909-16.

22. Bailis DS, Segall A, Chipperfield JG. Two views of self-rated general health status. Soc Sci Med. 2003;56(2):203-17.

23. Bowling A. Just one question: If one question works, why ask several? J Epidemiol Community Health. 2005:59(5):342-5.

24. Rowlings PA, Przepiorka D, Klein JP, Gale RP, Passweg JR, Henslee-Downey PJ, et al. IBMTR severity index for grading acute graft-versus-host disease: Retrospective comparison with glucksberg grade. $\mathrm{Br} J$ Haematol. 1997;97(4):855-64

25. Bearman SI, Appelbaum FR, Buckner CD, Petersen FB, Fisher LD, Clift RA, et al. Regimen-related toxicity in patients undergoing bone marrow transplantation. J Clin Oncol. 1988;6(10):1562-8.

26. National Cancer Institute. Common Terminology Criteria for Adverse Events (CTCA). http://evs.nci.nih.gov/ftp1/CTCAE/CTCAE_4.03_2010-064_QuickReference_5x7.pdf; accessed 4-4-2015.

27. Shulman HM, Sullivan KM, Weiden PL, McDonald GB, Striker GE, Sale GE, et al. Chronic graft-versus-host syndrome in man. A long-term clinicopathologic study of 20 seattle patients. Am J Med. 1980;69(2):204-17.

28. Applebaum FR, Forman SJ, Negrin RS, et al., editors. Hematopoietic cel transplantation, $4^{\text {th }}$ ed. Malden, Massachusetts: Blackwell Science; 2009.

29. Kim J, Mueller CW. Factor Analysis: Statistical methods and practical issues. Newbury Park, California: Sage publications; 1978.

30. Cronbach $L$, Warrington WG. Time-limit tests: Estimating their reliability and degree of speeding. Psychometrika. 1951;16(2):167-88.

31. Nunnally JC, Bernstein $\mathrm{IH}$, Berge JMT. Psychometric theory. New York: McGraw-Hill; 1967.

32. Landis JR, Koch GG. An application of hierarchical kappa-type statistics in the assessment of majority agreement among multiple observers. Biometrics. 1977:33(2):363-74.

33. Hedeker D, Gibbons RD. Application of random-effects pattern-mixture models for missing data in longitudinal studies. Psychol Methods. 1997;2(1):64-78.

34. Mayer DK, Ratichek S, Berhe H, Stewart S, McTavish F, Gustafson D, et al. Development of a health-related website for parents of children receiving hematopoietic stem cell transplant: HSCT-CHESS. J Cancer Surviv. 2010;4(1):67-73

\section{Submit your next manuscript to BioMed Central and take full advantage of:}

- Convenient online submission

- Thorough peer review

- No space constraints or color figure charges

- Immediate publication on acceptance

- Inclusion in PubMed, CAS, Scopus and Google Scholar

- Research which is freely available for redistribution 